in honoraria, about $\$ 260,000$ of it from pharmaceutical companies. And since 1980, it says, OMRC has received almost $\$ 3.5$ million from pharmaceutical companies. The committee says this "gives the appearance of a conflict of interest".

But the committee found no favourable bias toward drug companies in the research results, largely on the grounds that the "the number of positive and negative studies were approximately equal".

Bluestone says he did not disclose the amounts he received because he "misinterpreted" the NIH instructions, but he claims that full descriptions of the industryfunded studies were described in progress reports. Speaking at the June congressional hearing, James Wyngaarden, former director of NIH, said that before 1985, the instructions were not clear. When they were made more explicit, he said, it was "quite possible that he [Bluestone] just didn't notice the new requirements and neither did we".

\section{Scientific dispute}

The new NIH committee now has the difficult task of unravelling the scientific issues in the dispute. Wyngaarden said that "some of the rather unusual steps Cantekin has taken might be viewed somewhat differently if his scientific views are sustained". But an independent consultant who reviewed the manuscripts for the university hearing board said "it may be that replication of the trial is the only way to resolve the current dispute". Congressman Ted Weiss, chairman of the subcommittee that held the June hearing (see Nature 339, 568; 1989), argues that the results of a subsequent study by OMRC also appear to show that amoxicillin is no more effective than a placebo. Bluestone denies this and says that the results were taken out of context. He also denies allegations made by Cantekin that he has intentionally delayed publication of the results. He claims that the manuscript is being submitted to NEJM this week. Cantekin asked to see a final report on the study prepared for NIH but his request was denied because the contents are patentable. The study was funded in part by the companies whose antibiotics were being studied.

Weiss is not satisfied with written answers he has received from Bluestone and plans to hold a hearing in the next few months at which Bluestone will testify for the first time. This case, he said "provides us with many examples of what should not be happening with NIH-funded studies". With its particular interest in how institutions handle misconduct cases, and in ensuring that whistleblowers are protected, the House of Representatives subcommittee on oversight and investigations, chaired by John Dingell, is also following the controversy closely.

Christine McGourty

\title{
JPL looks beyond Voyager
}

\section{Pasadena}

As the Voyager 2 spacecraft sped past Neptune last week and off into the furthermost reaches of space (see page $665)$, it marked the end of the first grand reconnaissance of the Solar System. It also highlighted a new era for the Jet Propulsion Laboratory, which manages the Voyager mission and many other unmanned space expeditions for NASA (the National Aeronautics and Space Administration).

After a stormy period of budget cuts, JPL is is basking in the warmth of President George Bush's support for space studies and is preparing itself for a new phase of exploration that will dictate its direction well into the next century.

Begun in the 1930s as an aeronautical laboratory for nearby California Institute of Technology (CalTech) and later serving as an Army research facility, JPL was turned over to NASA when the agency was created in 1958. Its assignment was to take the lead in the unmanned exploration of the Solar System. Besides the twin Voyagers, early missions included the Mariner series that explored the inner planets and the Viking journey to Mars. But while scientists are still reaping the benefits of these missions, the launch of the last Voyager in 1977 meant that JPL had to look to new venues for its bread and butter.

The time of the Voyager launch coincided with a period of waning federal support for the space programme that reached its nadir with budget and staff cuts in 1982. The crisis prompted a decision to accept funds from other government agencies - most notably the Department of Defense - and set off an uproar at both JPL and CalTech, which through a unique arrangement pays the salaries of the laboratory employees. But the move bolstered JPL's research base. And since 1983, the facility has enjoyed steady increases in support that have brought its

\section{ANIMAL RIGHTS \\ Monkeys go home}

\section{Paris}

A Lyons tribunal decided on Tuesday 22 August to order the return of 28 monkeys to the research laboratory from which they were stolen in May. The monkeys had been held at a primate centre in Strasbourg. Meanwhile, eight members of an antivivisection organization, Arche de Noé, are awaiting trial for the break-in.

During the night of 19 August, the Front de libération des animaux, broke into kennels in northern France, releasing 28 beagles belonging to a small company which carries out toxicity trials on drugs intended for humans. annual budget to a little over $\$ 1,000$ million and its staff to 5,200 , of whom more than half are engineers and scientists.

The laboratory's strategy for the rest of the century and beyond focuses on three general areas - additional Solar System studies, investigation of the Earth itself and studies of other solar systems.

The first category includes some missions planned long ago but only now getting under way. Among them are the Galileo mission to Jupiter, which has an October launch date, and the Mars Observer, which is scheduled for 1992. Both are projects the laboratory had hoped to complete in the early $1980 \mathrm{~s}$. Future plans include the Cassini mission to Saturn, which will be the first JPL craft to employ 1980 s technology. Also in the planning stages are efforts to build automated rovers that would land on planets and satellites and return surface samples to Earth. "We are now getting into a new phase of science - the 'in situ' robotic exploration of the Solar System", says the laboratory's chief scientist, Moustafa Chahine.

For most of JPL's history, Earth had been ignored. Ten years ago, the laboratory formed an Earth and Space Sciences Division. More recently, JPL scientists began working on the Earth Observing System (EOS), a gigantic undertaking involving at least two space-based platforms, the first of which is due to be launched in 1996. All told, JPL scientists designed and developed 11 instruments nearly a third of the total payload - that will fly aboard the two EOS platforms.

Each step in JPL's evolution has meant new developments in microelectronics, information systems, image processing and computer systems to help analyse the data gathered. One new system involves the hypercube, a parallel computer pioneered at CalTech. JPL scientists are working on a system, Mark $3 \mathrm{fp}$, that interconnects up to 128 processing nodes that can each tackle the same or different tasks. The system will be able to combine data from different sources - microwaves, radio waves, infrared and visible light - into a multi-dimensional image that make it possible to see directly patterns in data that are normally hidden in piles of computer print-outs.

Despite such new projects, some critics say JPL is showing its age. Director Lew Allen disputes that vigorously, saying a crop of new scientists has moved in alongside the laboratory veterans. $\mathrm{He}$ is more worried that the long gaps between missions have left his crew rusty. Since one mistake can cost years of planning, he notes, "you clearly worry a great deal about whether your skills are up to snuff".

Robert Buderi 